support her claim. Throughout the book there are far too many tendentious assertions in this vein without support or explanation, and a tendency to use quotation instead of argument.

My second criticism is that implications of concepts discussed are not really brought out. For example: a particular kind of individualism is criticised for being 'possessive'. But can any kind of individualism avoid being possessive in some measure, even if only of its own ideas and beliefs? (But in many ways I thought the chapter on the individual and the community the best in the book.) Again, if freedom is to be defined as "consciousness, moral awareness and the capacity to choose between actions and enter into beliefs' (p 95), can anything impair it, even the gross inequalities which are said to damage it ? These and others like them are of course large questions. I would not expect a full scale discussion of them but would have welcomed an acknowledgement that they do arise from any attempt to analyse the concepts discussed in this book.

ELIZABETH TELFER

Department of Moral Philosophy University of Glasgow

\section{Ethics in Nursing Practice and} Education

(American Nurses' Association) 1980 $65 \mathrm{pp} \$ 4.50$.

A nurse in the 1980 s may be confronted with a variety of complex issues, for which the custom and practice of the past is no longer a sufficient guide. Technical progress has created dilemmas which did not previously exist on the one hand, and on the other there is diversity of opinion where once there was a consensus. In addition, the nurse is also assuming an ever expanding role, especially when functioning as an independent practitioner away from the hierarchical hospital structure. The need for some kind of comprehensive text, like that of the British Medical Association's Handbook of Medical Ethics is indisputable. Any attempt to fill this gap must be welcomed.

This collection of seven papers from the American Nurses' Association sets out to consider two main areas, that of nursing practice and of nursing education. In the former the approach is mainly academic and tends to avoid coming to grips in a specific way with particular issues. There is some overlapping in the different papers, particularly in discussing a definition of ethics. It has also to be remembered that the training and context of practice of health care in America is at considerable variance with our own in Britain, not least in the matter of private funding. For any nurse seeking guidance, the Royal College of Nurses' Code of Professional Conduct is likely to prove as helpful.

The papers in the Education section are much more specific, and recognise the need for including a course of ethics in a nursing curriculum. The third paper, 'A Bioethical Program for Baccalaureate Nursing Students', gives an outline of the sort of approach that might be used in such a course. This is not only excellent as a model in this subject but is also valuable as an approach for teaching in any subject.

The British Medical Association's Handbook covers a whole range of issues thoroughly and sensitively; but only a page or so is devoted to nurses, and that in the context of their relationship to doctors. While the RCN has gone some way to meeting the need for a treatment of the special problems of nurses with such booklets as Guidelines on Confidentiality there is still a lack of a comprehensive British work on the subject.

P M KILSHAW Imperial College, University of London

\section{Muted Consent}

Jan Wojcik. Purdue University, Indiana, USA, 1978. I64 pp $\$ 3.35$.

This volume is one of a series on science, technology and human values from the Purdue University, West Lafayette, Indiana, USA. The author hopes that the book will be used as a 'primer in the language of medical ethics'. The book, in seven chapters, looks at various topics in medical ethics. Each chapter begins with three fictional case histories which illustrate the problems analysed in each chapter. The debate is clear and well illustrated with a number of references to contemporary commentators. The treatment of the material is mainly theoretical and philosophical. The quality of the case material is reduced by the fact that cases are hypothetical and the final outcome is not given. Often the complexity of cases illustrates te many principles that co-exist of considering case material. This bogk isolates the major stances taken debate on the issues covered. $\overline{\bar{c}}$

It seems unclear if the book intended for doctors, medical students, nurses, philosophers, theologians or the general publi The cases and the discussion suffer very much from bias towards the United States. Indeed the involve ment of the courts of law both cizl and criminal is very different in the two countries and the arguments thus suffer. Certainly some of the language is more suited to the philosopher than the medical studept or young doctor trying to make sense of the dilemmas which face him.

The basic theme of the book that all ethical problems have am involvement with altered consent some form or another. Even if oge cannot go the whole way with this interesting thesis it undoubted 6 emphasises a very important message. Consent in its widest sense t8 essential for good ethical doctoring. However, in some areas the proble is not merely of consent but who can give valid consent. Can the moth give consent for the death of het child or fetus? We accept that the parents must be involved in de cisions about their baby especially it is suffering from a serious cow. genital malformation. In the area of death and dying can the patient gi valid consent in a situation where is denied any real alternative? One chapter explores at considerable length the technical aspects of deat Other aspects receive less attention in particular the development of the hospice movement in this countris The chapter on resource allocation clear and I enjoyed reading it ven much. Again it has a US bias emphasing the close involvement of the law courts.

I cannot advise any medical student to buy this book or ever suggest it as a primer, but, for thos interested in medical ethics this is valuable source book. The references are extensive and the arguments $\mathrm{\Phi}$ the various commentators are we 9 summarised. A book for the libraro rather than for the private collection

B T POTTER Royal Infirmary Edinburg身 